\title{
Investment and Circulating Funds Strategies in Sport Industry in China
}

To Establish the Investing Funds in Sport Industry in Our Country

\author{
Yue Wenyan \\ (Jinan University, Guangzhou 510632)
}

Key Words: sport industry; investment; circulate funds; funds

\begin{abstract}
This essay is going to discuss the possibilities and necessities to develop the sport industry in our country by using the investing and circulating funds. It analyzes the strategies and the ways to operate the funds, and it puts forwards several suggestions on development of the investment funds, the modes of operating the funds, the ways to organize it, etc,.

There is no single standard to define the sport industry. In this essay, the sport industry refers to the enterprises producing and offering sport services or products, that is, the collections of all kinds of enterprises which provide the intangible products with labor services. There are two reasons to define the sport industry. Firstly, It fits the three levels of industry division put forward by Fisher; Secondly, the essay can focus on the investing and circulating funds systems of the providing the intangible products in sport industry. Because the producing the sport suits and the facilities are closely connected with the manufactory industry, which is quite different from the investing and circulating fund system.
\end{abstract}

\section{The general introduction of industrial investment fund}

Investment fund refers to trust fund which the investors purchase the profitable stocks which released to the public, then put them in the charge of the experts, mainly investing to stocks or negotiable securities; the investors with share the profits and responsibilities according to their investment. The investing fund firstly generated from the $18^{\text {th }}$ England. After the industrial revolution, the productive forces of England strengthened greatly, lots of money was invested to the overseas (mainly the American Continent). But the investment was confined to the lacking of special knowledge of international investment and the differences in languages and cultures. In the constantly conflict between the investment will and investment abilities, the investment fund--the new investment tool-was generated. Industrial investment fund mainly refers to the collective investment system, in which the investment fund exists and operates, and was mainly invested to the non-listed companies. The characteristics of the industrial investment fund lies in collective investment, operated by experts, decentralized risks, common profits, regular operation. That is to say, the experts with certain knowledge of decentralized investment collect the money and put it to the new technological industry in order to get profits.

The industrial investment fund receives more focus in recent years. That was because the traditional modes of operating the enterprise can not satisfy the needs of the newly and up-grated hi-tech enterprises. So the industrial investment fund generates and successfully producing a series of advanced hi-tech enterprise such as Microsoft, Intel, and Yahoo.

The industrial investment fund has shown its unique advantages in operating hi-tech enterprises. But it does not mean that it can only be used to the hi-tech fields, or supported the investment and circulation funds in the high technology. The truth is, when the operating modes of the industrial investment fund succeeded in America, many countries are trying to joint it with the industrial policies, and they made huge success.

\section{The Analysis of Possibility and Necessity of the Joint Development of the Sport Industry} and the Industrial Investment Fund in China

\subsection{The analysis of the possibility}

As it was discussed in the previous section, many countries use the operating modes of America 
in operating the investment and circulating fund, the venture Capital, in the hi-tech industry, accumulate a wealth of experience, reform it, and try to make it better. It is proved that based on the good knowledge of economic development, political structures and social cultures in our own country, it is possible to use the industrial investment fund and implement it to the priority industries, which may be the hi-tech industries or some other basic industry or potential newly-developed industry. While the sport industry fits well to jointly develop the industrial investment fund. It can be presented in the following aspects:

Firstly, the sport industry is a potential industry with the value of investment. With the constant development of the economy, the citizens have more money and more leisure time to spend in the sport industry. According to a research, between 1994 and 1998, the sport consume of the citizens tends to 1.5. It can be predicted that people will spend more money on the sport items in terms of livelihood, entertainment and development.

Secondly, the sport industry has indispensible basic contribution to the steadily increase of the national economy. The well development of the sport industry will offer people with vast room for the sport consumption. More importantly, it will improve effectively the efficiency of the workers and reduce the output on the medical treatment. The government of Canada carried out a research in 1995 about the relationship between the sport involvement and the productive forces. The result showed that the sport involvement increased by $25 \%$, the national economy would increase by $0.255-1.5 \%$. the sport activity improved the national labor force by $0.75 \%$, among them, the labor force of the white-collared workers was higher than that of the non-sport workers by $12.5 \%$ (Fan Chengling, 2002).

Thirdly, the sport industry has a high relative relationship with the other industries in national economy. A research carried out by an American economist showed that the sport industry has a strong relationship with many industrial fields (Table 1). The American economist Siequin performed the substantial evidence research. It showed that the strength of the relationship between different industries may boom the national economy. So, the development of the sport industry may improve the development of the industries related with the sport industry, and improve the national economy at the same time.

Examined from the previous characteristics, the sport industry is a new industry which deserves investment and potential profits. On a second level, it may play an important role in the constant development of the national economy. We can make use of the modes of the industrial investment fund to develop the sport industry, to upgrade the national economic growth, to improve people's life.

Table 1 The relationship between the sport industry and some other industries

\begin{tabular}{|c|c|c|c|c|c|c|}
\hline & Travelling & clothing & communication & architecture & food & manufacture \\
\hline cognation & 0.21 & 0.13 & 0.12 & 0.11 & 0.014 & 0.008 \\
\hline strong/weak & strong & strong & strong & strong & strong & strong \\
\hline
\end{tabular}

Note: see the reference in the bibliography (12).

\subsection{The analysis of the necessity}

The sport investment and circulation system is not suitable for the development of the sport industry. On the one hand, the input of the sport industry mainly depends on the national finance. There are barriers for the social capital to get involved. The input for the sports from the government are inadequate; the rate of the output between the sports and the nations finance is low; the financial input is not balance between the pulic sport and the competitive sport, the Olympic sports and non-Olympic sports, high-level sports team and reserve sports team; the financial input between the central and the local government are not balanced; furthermore, the economic policies in sport industry cannot fit well with the management system.

The investment fund can collect effectively social capital to invest the sport industry, to solve the inadequate input of the national finance. Besides, the shares or the investment of the non-public enterprises or the national enterprises may make it clear about the duty and the responsibilities, to establish a more reasonable system to put forward the reform of the modern enterprises in sport 
industry. It is really necessary to jointly develop the sport industry with the industrial investment fund.

\section{Thoughts about the strategies of developing the Sport industrial investment fund}

Generally speaking, the investors put their money into the industrial investment funds do not aim at the short-term interest, but the growth of the industry and the increase in value, that is, the predictable prospect and steady profits of the industry. In our country, it is necessary to develop the sport industry with the industrial capital with a basic understanding of the economic structures. More specifically, to concentrate on the development of the sport industry should be based on the system construction of the government and the foster of the specialized experts at financial investment and sport industry. That is, to establish the sport industrial fund is the major task; at the same time, we should not ignore the construction of the governmental structure and the foster of the experts to manage the fund.

\subsection{The construction of the whole set of structure for the government}

The fund industry began to form a system over ten years of development. But there is no official Trust Law published up to now. There are some temporary methods and regulations to stipulate the vast market of fund industry. The problem is, the smooth development of the investment fund and the good use of its economic function need to strictly regulate the duties and the responsibilities of the founders, the managers and the general investors of the fund. It is more important to preserve the rights and profits of the common middle-sized or small-sized investors. It is necessary to establish a whole system of laws and regulations about industrial investment fund, to check up on the qualification of the founders, to confine the responsibilities of the investors, the managers and the trustees. It is equally important to regulate the release of the news about the fund, to complete the financial and auditing system, to reduce the risks of the industrial investment fund as a system.

\subsection{Localization of the knowledge and foster of the experts}

\subsubsection{Knowledge of operating the funds must be localized}

The knowledge we learned from the textbooks introduces us the general rule the things operates. While implementing it into the industry with the Chinese characteristics, we must generate the fund management techniques and systems with Chinese characteristics as well, according to the fact existing in our country. Otherwise, we will follow the track of the fund industry in 1990-1996, which required the invested enterprises had the record of three-years increase of profit, ignoring the fact that the serious problem of rebuilding of the industry and the short-term life cycle of the products, as a result, there would be no room for profits even if input the fund. We need to study and consider the specialty of the economic development and the sport industry while stabling the sport investment fund.

\subsubsection{Foster the experts}

Conducting financial transactions is the basic and central part of the investment fund. The quantity of the financiers will determine the survival and development of the investment fund. A team of experts who are good at the fund and familiar with the operating the sport industry and the enterprises must be set up as soon as possible. The team of lawyers, accountants, auditors, and property assessment experts must be grouped which will provide services for the industrial investment fund.

\section{References}

[1] Rao Yuan, Cong Huping, Zhang Yungang, etc, (eds.), Sports Industry Development and Research in Yunnan Province. Kunming: Yunnan Scientific Press, 2000, 20-45.

[2]Fan Chengling, Ge Shulin. Governmental Interfere of the National Health-Report on Improving the Citizen's Health, Enlarging the Sport Consumption, China Sports Science and Technology, 2002, 38 (3):18-24.

[3]. Liu Minlian, Fu Gege, Wang Lifang, etc, Research of the Stock Structure and China's Professional Football Reform and Development . Chinese Sport Technology, 2002. 38(3): 40-42. 